\title{
Glial Cells as Therapeutic Targets for ALS
}

\author{
Amanda M. Haidet-Phillips and Nicholas J. Maragakis \\ Department of Neurology, Johns Hopkins University, Baltimore, Maryland,
}

USA

\section{Introduction}

Although Amyotrophic Lateral Sclerosis (ALS) is a neurodegenerative disease characterized by motor neuron death, recent studies now implicate the non-neuronal environment as a major contributor to motor neuron loss. This body of evidence has been amassed over the past 10-15 years and highlights glial cells as new therapeutic targets for ALS. Glial cells, once thought to be simply the "glue" of the central nervous system (CNS), are now realized to actively participate in neural transmission and serve complex roles in regulation of the CNS environment.

Several glial cell types including astrocytes, microglia, and oligodendrocytes exist in the CNS; each serves a distinct function. Astrocytes comprise the majority of the CNS cellular space and act to regulate neurotransmitter concentrations at synapses, provide trophic support for neurons, and maintain metabolic and ionic homeostasis. Astrocytes can participate in the immune response, however, microglia serve as the resident immune cell of the CNS. Microglia are mobile, phagocytic, and constantly screening the CNS for possible infection or injury. Upon activation, microglia can secrete pro-inflammatory cytokines and chemokines to promote the clearance of any infectious agents and recruit other immune cells to the site of injury. Depending on the stimuli, microglia also are known to release neurotrophic growth factors and anti-inflammatory molecules to aid in repair and resolution of neural damage. Oligodendrocytes are the myelinating glia of the CNS which intimately interact with, and provide metabolic support to neurons. Oligodendrocytes are capable of producing myelin sheaths which insulate axons and aid in the conduction of action potentials.

Ongoing research strives to define exactly how glial cells affect motor neuron survival in ALS. Furthermore, translation of these studies to the clinical setting begs for novel approaches to treat this new target for ALS.

\section{Non-neuronal cells contribute to motor neuron death in ALS}

The bulk of work on glial cells in ALS is derived from studies in rodent ALS models. The most widely used ALS models are rodents that ubiquitously express the human mutant superoxide dismutase 1 (SOD1) protein associated with dominantly-inherited familial ALS (fALS) (Gurney et al., 1994). Currently, 12 different SOD1 mutations have been expressed in lines of transgenic mice leading to development of motor neuron disease. By far, the most commonly used model is the SOD1 G93A mutant mouse which contains 25 copies of the 
human SOD1 G93A transgene corresponding to a 10-15 fold increase in SOD1 protein (Chiu et al., 1995; Gurney et al., 1994). These mice develop a severe motor neuron disease which resembles many of the clinical and pathological features of human ALS. One of the first indications that non-neuronal cells were involved in disease came from studies where the mutant SOD1 gene was expressed only in neurons instead of ubiquitously. Lines of transgenic mice were generated where mutant SOD1 expression was driven by either the Thy1 promoter or neurofilament light chain promoter (Jaarsma et al., 2008; Lino et al., 2002; Pramatarova et al., 2001). In two of these three studies (Lino et al., 2002; Pramatarova et al., 2001), the mice did not develop any neurological disease phenotype leading to the hypothesis that mutant SOD1 must be expressed in multiple cell types to trigger ALS. A subsequent study did report motor neuron disease with neuronal mutant SOD1 expression, however, the disease onset was very late ( $\sim 500$ days of age) and highly variable, suggesting a possible contribution of mutant non-neuronal cells in disease (Jaarsma et al., 2008).

Further studies combining various approaches continue to support this hypothesis (Clement et al., 2003; Miller et al., 2005). To evaluate the contribution of mutant SOD1 expression in different cell populations, chimeric mice were generated from a mixture of wild-type cells and cells that expressed mutant SOD1 (Clement et al., 2003). It was observed that mice with a greater proportion of wild-type cells to mutant SOD1 cells had extended survival. In addition, motor neurons expressing mutant SOD1 that were surrounded by wild-type nonneuronal cells had less severe pathology. Likewise, wild-type motor neurons surrounded by non-neuronal cells expressing mutant SOD1 appeared to be degenerating, suggesting that neighboring non-neuronal cells may play a direct role in the death of MNs. To more directly discern the contribution of mutant SOD1 in motor neurons, transgenic mice were created where mutant SOD1 was removed by $\mathrm{Hb} 9$-driven cre recombinase solely in motor neurons. Although these mice have greatly reduced mutant SOD1 expression in motor neurons, they still develop motor neuron disease albeit a significant delay in disease onset (Boillee et al., 2006a). Furthermore, targeting only the motor neurons with an siRNA to reduce mutant SOD1 levels showed only a transient effect of motor neuron protection, suggesting that other cell types were contributing to the ultimate demise of motor neurons (Miller et al., 2005). Collectively, these studies suggest that ALS is a non-cell autonomous disease; nonneuronal mutant SOD1-expressing cells can directly cause wild-type motor neurons to exhibit a disease phenotype.

\subsection{Astrocytes influence the course of disease in ALS}

Specific populations of glial cells have been analyzed to determine their precise role in motor neuron death in ALS. Astrocytes are glial cells with diverse roles including regulation of the extracellular CNS environment, maintenance of cell-cell communication, CNS vascular control, growth factor production, and neurotransmitter metabolism (Maragakis \& Rothstein, 2006). Astrocytes can also become reactive and proliferative in response to neuronal death or CNS injury. Indeed, reactive astrocytosis and inflammation are prominent features in both the human ALS spinal cord as well as in rodent ALS models. Moreover, astrocytes have long been suspected to exacerbate motor neuron death due to their reported loss of glial glutamate transporter 1 (GLT1) [excitatory amino acid transporter 2 (EAAT2) in humans](Bendotti et al., 2001; Bristol \& Rothstein, 1996; Bruijn et al., 1997; Rothstein et al., 1995). GLT1 is a glutamate transporter responsible for removing $90 \%$ of the extrasynaptic glutamate to prevent continued neuronal firing. Increased levels 
of glutamate have been found in the cerebrospinal fluid of ALS patients (Rothstein et al., 1990; Shaw et al., 1995). Chronic reduction in glutamate uptake results in a buildup of extracellular glutamate, leading to increased neuronal synaptic transmission and excitotoxic neuronal death. The ALS-linked GLT1 loss is found in both human ALS and in several rodent models and signifies astrocyte pathology as consistent theme in ALS pathobiology. However, it is difficult to discern whether astrocytes become dysfunctional due to motor neuron degeneration or whether dysfunction is a secondary event in the disease course.

Recent studies aim to answer these questions by evaluating how mutant SOD1 expression in astrocytes affects disease course in the mutant SOD1 mouse model. In these sets of experiments, cre recombinase was driven using the GFAP promoter to excise the floxed mutant SOD1 gene solely in astrocytes. Depending on which SOD1 mutation was present, the reduction of mutant SOD1 in astrocytes either slows disease progression (SOD1 G37R)(Yamanaka et al., 2008b) or slows disease onset and progression (SOD1 G85R)(Wang et al., 2011). Microgliosis was reduced and astrocytic GLT1 expression was maintained in one study (Wang et al., 2011), however, the exact mechanism for prolonged survival in these mice is still undefined. Nevertheless, it seems that the mutant SOD1 protein directly causes astrocytes to become aberrant in the SOD1 mouse model and rescue of diseased astrocytes can significantly influence disease course. It is also interesting to note that complete ablation of proliferating mutant SOD1 astrocytes in the SOD1 mouse model does not affect any measure of motor neuron disease in these mice. Therefore, astrocyte proliferation itself or the presence of mutant SOD1 in the proliferating astrocyte population does not seem to contribute to motor neuron degeneration (Lepore et al., 2008a).

\subsection{Microglia direct disease progression in ALS mouse models}

In addition to astrocytes, microglia are another important glial cell type in ALS pathogenesis due to their phagocytic properties and capacity to produce a wide array of cytokines and chemokines, attracting other cells to the site of injury. Indeed, extensive microglial activation and proliferation characterizes sites of motor neuron injury in human ALS and rodent models and this microgliosis increases as disease worsens (Henkel et al., 2009). Interestingly, investigations are ongoing as to whether microglia are neuroprotective, neurotoxic, or situationally both in ALS.

To directly assess the role of mutant SOD1 in microglia of the SOD1 mouse model, two parallel studies sought to remove the mutant SOD1 G37R specifically from microglia in these transgenic mice. In one study, the floxed mutant SOD1 gene was excised from microglia using cre recombinase driven by the $\mathrm{Cd} 11 \mathrm{~b}$ promoter, removing the gene from microglia and peripheral macrophages only (Boillee et al., 2006b). In the other parallel study, microglia were genetically ablated in the mutant SOD1 mouse followed by reconstitution with wild-type microglia through a bone-marrow transplant (Beers et al., 2006). The result from both studies was a slowed disease progression resulting in a dramatic extension in life in these mice. More recently, an additional study also showed slowed disease progression when a different SOD1 mutant, SOD1 G85R, was excised by cre recombinase solely in microglia (Wang et al., 2009). Collectively, these studies suggest the presence of mutant SOD1 in microglia causes these cells to adopt a more neurotoxic phenotype and directly affects motor neuron survival in the mutant SOD1 mouse model. 
Other studies suggest that microglia may actually play a neuroprotective role in motor neuron disease. Evidence from other disease and injury models indicates that as microglia become activated, they can adopt either an "M1" proinflammatory phenotype or an "M2" alternatively activated phenotype leading to secretion of anti-inflammatory cytokines and neurotrophic factors (Henkel et al., 2009). Although mutant SOD1 expression seems to cause microglia to lean toward proinflammatory M1 activation, microglia have also been shown to produce anti-inflammatory cytokines and neuroprotective growth factors during the early phase of disease in the ALS mice (Chiu et al., 2008). Interestingly, several studies have indicated that $\mathrm{T}$ cells directly influence microglial activation and their differentiation toward a neuroprotective or proinflammatory phenotype. When SOD1 G93A mice were bred with a strain of mice lacking $\mathrm{T}$ cells, disease course was accelerated and this worsening of disease was accompanied by a decrease in alternative M2 microglial activation, although astrocytosis remained unchanged (Chiu et al., 2008). In addition, increased numbers of regulatory $\mathrm{T}$ cells are associated with the stable phase of disease in both mice and ALS patients and these regulatory $\mathrm{T}$ cells can promote microglia to adopt an anti-inflammatory M2 phenotype (Beers et al., 2011). Over the course of disease, these regulatory $\mathrm{T}$ cells decrease in number accompanied by a shift in microglia from protective M2 to the proinflammatory M1 phenotype. Therefore, this evidence suggests microglia adopt an activated neuroprotective M2 phenotype during early disease, but then develop into proinflammatory M1 microglia as disease progresses. Therapeutic approaches that promote M2 microglial differentiation or maintenance may prove to be an alternative to the limitation of microglial activation.

\subsection{The undefined role of oligodendrocytes and their progenitors in ALS}

While focus has been on the involvement of neurons, astrocytes and microglia in ALS pathogenesis, a few studies have investigated other glial cell lineages as well. In particular, myelinating oligodendrocytes of the central nervous system and Schwann cells of the peripheral nervous system form intimate connections with motor neurons and their axons, promote neuronal health through production of neurotrophic factors, and aid in regeneration after neuronal injury. Surprisingly little is known about the role of Schwann cells and oligodendrocytes in ALS, although pathological aberrations in myelin have been reported along peripheral nerves in human patients (Perrie et al., 1993). As with glial inflammation, these myelin abnormalities may be primary or secondary to motor neuron degeneration. To specifically investigate whether mutant SOD1 alters Schwann cells, transgenic mice were created with SOD1 G93A expression restricted to myelinating Schwann cells using the myelin protein zero (P0) promoter (Turner et al., 2010). No evidence of motor neuron disease was observed in these mice, suggesting the mutant SOD1 protein is not detrimental to this Schwann cell population. In contrast, the specific removal of floxed mutant SOD1 in Schwann cells by P0-driven cre recombinase seems to modestly accelerate disease progression in the SOD1 G37R mice (Lobsiger et al., 2009). This curious disease acceleration is hypothesized to be a result of reducing SOD1's normal dismutase activity in Schwann cells, which may serve an unrealized neuroprotective function during the nerve regeneration process. Thus, a clear role of mutant SOD1-expressing Schwann cells has not been determined in rodent ALS models. 
Another open question in the field is whether oligodendrocytes and their NG2+ progenitor cells directly affect motor neuron loss in ALS. To date, only one study has investigated how mutant SOD1 in oligodendrocytes influences motor neuron loss and the experimental design causes the results to be difficult to interpret. In this study, chimeric mice were created by mixing embryonic cells expressing SOD1 G37R with wild-type cells lacking the Olig1 transcription factor (Yamanaka et al., 2008a). The Olig1 -/- mice are unable to form motor neurons or oligodendrocytes. Therefore, the motor neurons and oligodendrocytes in the chimeric mice were generated from the mutant SOD1 G37R cells which have normal Olig1 levels. The result is a chimeric mouse with mutant motor neurons and oligodendrocytes, but with all other cells being a mixture of mutant and wild-type cells. These mice did not develop the motor neuron disease typical in the SOD1 G37R mouse model and the authors suggest that mutant SOD1 expression in oligodendrocytes is not a significant contributor to motor neuron degeneration. However, technical limitations prohibited verifying that all oligodendrocytes expressed the mutant SOD1 so it is difficult to draw a strong conclusion from these studies.

Interest in the oligodendrocyte progenitor cells, also called NG2+ cells, has risen in the ALS field due to recent reports of their aberrant proliferation in rodent models. These NG2+ cells are found widely throughout the CNS and are mitotically active, especially in areas of injury or neuronal degeneration. Although the specific functions of these cells is still under investigation, these $\mathrm{NG} 2+$ cells can divide and differentiate into myelinating oligodendrocytes, but not into astrocytes or neurons in vivo (Kang et al., 2010). Several studies have reported a dramatic (20-fold) increase in proliferation of NG2+ cells over the course of disease in ALS mouse models, with NG2+ cells contributing to over half of the total dividing cell population in the spinal cord of symptomatic mice (Kang et al., 2010; Lepore et al., 2008a; Magnus et al., 2008). Differentiation of these NG2+ cells into oligodendrocytes is also enhanced in mutant SOD1 mice compared to wild-type mice for reasons still unknown (Kang et al., 2010). It has been proposed that oligodendrocytes undergo degeneration in response to motor neuron loss and the NG2+ cell proliferation and differentiation is an attempt to restore these lost oligodendrocytes. However, it will be crucial to dissect what effects are primary and secondary to motor neuron loss and what role, if any, NG2+ cells play in disease course. Studies investigating how mutant SOD1 influences normal NG2+ cell behavior are warranted, including analysis of whether mutant SOD1 NG2+ cells share a similar non-cell autonomous toxicity as astrocytes and microglia.

\subsection{Glial cell involvement in TDP43/FUS ALS?}

A defining pathological feature in post-mortem ALS tissue is ubiquitin-positive inclusions within neurons and glia in the spinal cord, brainstem, and motor cortex. In patients with SOD1 mutations, these inclusions contain misfolded SOD1 protein (Bruijn et al., 1998). However, in ALS patients lacking SOD1 mutations, these inclusions contain one of two RNA/DNA binding proteins: TAR DNA-binding protein 43 (TDP43) or fused in sarcoma protein (FUS) (Kwiatkowski et al., 2009; Mackenzie et al., 2007; Neumann et al., 2006; Vance et al., 2009). Genetic analyses have also revealed disease-linked mutations in both TDP43 and FUS in subsets of familial and few sporadic ALS patients, adding to evidence that these proteins are involved in ALS pathogenesis (Kabashi et al., 2008; Kwiatkowski et al., 2009; Sreedharan et al., 2008; Vance et al., 2009). However, a major question that remains is whether glial cells play an active role in ALS disease caused by TDP43 or FUS mutations. 
Animal models are in development to better understand pathological disease mechanisms in TDP43 and FUS ALS. Thus far, a number of rodent models have been described for TDP43 ALS and these models vary in the TDP43 mutations expressed and the promoter used to drive expression (Cohen et al., 2011). The phenotypes observed in these models have been somewhat perplexing due to the difficulties in dissecting the effects of human TDP43 protein overexpression from mutant-specific effects. Nonetheless, a common theme in these animals is neurodegeneration accompanied by neuronal cytoplasmic aggregates in affected regions. None of the models to this point have reported glial pathology other than an increase in gliosis at sites of neuronal injury which may be secondary to neuronal death. Likewise, in the first reported rodent model for FUS ALS, astrogliosis and microgliosis were the only noted glial-specific pathologies (Huang et al., 2011). In contrast, TDP43- and FUSpositive inclusions are found in glial cells in post-mortem ALS spinal cord and it is difficult to know whether these inclusions were overlooked in the early animal models or whether they represent a discrepancy between human ALS and rodent models (Mackenzie et al., 2010). Careful dissection of the effects of mutant TDP43 and FUS in astrocytes, microglia, and oligodendrocytes (as well as NG2+ progenitors) will be essential to determine whether the non-cell autonomous disease nature extensively noted in SOD1 ALS is also recapitulated in TDP43- and FUS-mediated ALS.

\section{ALS disease modeling using glial cells}

Transgenic mouse models have played a key role in elucidating how glial cells affect the disease course of ALS. There are obvious advantages to in vivo models; however, it is often difficult to dissect the specific contributions of various cell populations from other influences in the CNS milieu. In parallel with these in vivo studies, several groups have established novel in vitro ALS models that recapitulate the glial-mediated motor neuron toxicity observed in transgenic ALS mouse models. Most of these in vitro models involve a co-culture where wildtype motor neurons are co-cultured with mutant SOD1 glia or wild-type glia. The goal is to determine the direct effects of diseased glia on motor neurons. Furthermore, in vitro models allow for the study of human cells derived from ALS patients. Most studies striving to correlate work from the ALS rodent model with human ALS rely on post-mortem tissue analysis, which makes it difficult to sort out primary contributors to motor neuron loss from secondary effects caused by neurodegeneration and the inflammatory response in the endstage spinal cord. These in vitro models provide a unique avenue to study human ALS in real-time and evaluate therapeutics and disease mechanisms.

\subsection{Motor neuron-glial cell co-cultures recapitulate glial-derived motor neuron damage}

Transgenic models have shown that removing the mutant SOD1 gene in microglia reduces motor neuron loss in the mutant SOD1 mouse model (Beers et al., 2006; Boillee et al., 2006b). Similar work has recapitulated this motor neuron loss using primary microglia isolated from mutant SOD1 mice in a co-culture with motor neurons. These studies have demonstrated that mutant SOD1-expressing microglia are more neurotoxic compared to wild-type microglia (Beers et al., 2006; Weydt et al., 2004; Xiao et al., 2007) which is not surprising given that mutant SOD1 microglia release an array of toxic inflammatory factors including 
nitric oxide, reactive oxygen species, TNF-a, and IL-1 (Almer et al., 1999; Henkel et al., 2009; Hensley et al., 2003; Nguyen et al., 2001; Sasaki et al., 2000; Weydt et al., 2004; Xiao et al., 2007). Motor neurons co-cultured with mutant SOD1-expressing microglia show a reduction in the number and length of neurites and reduced survival in the co-culture paradigm (Xiao et al., 2007). In addition, microglia treated with extracellular mutant SOD1 protein become inflamed and damaging to motor neurons in co-culture (Urushitani et al., 2006; Zhao et al., 2010). The extracellular mutant SOD1 only caused motor neuron death when microglia were added into the culture, indicating the motor neuron damage was directly initiated by microglia (Zhao et al., 2010). These in vitro systems could provide a platform for testing therapeutics that could potentially block neurotoxic microglia. For example, in vitro treatment with IL-4 caused mutant SOD1-expressing microglia to differentiate from an "M1" proinflammatory phenotype to an "M2" neuroprotective phenotype and improved motor neuron survival in co-culture (Zhao et al., 2006). It remains to be determined whether IL-4 will have the same effect when delivered to microglia in vivo. More efforts have focused on studying aberrant astrocyte function in mutant SOD1-based in vitro ALS models. Several studies have demonstrated that astrocytes isolated from mutant SOD1 mice (Di Giorgio et al., 2007; Nagai et al., 2007) as well as astrocytes derived from neural stem cells from these mice (Dodge et al., 2008) are toxic to wild-type motor neurons in co-culture. In these studies, primary motor neurons as well as motor neurons derived from mouse embryonic stem cells were shown to die more quickly in vitro when cultured on top of SOD1 G93A astrocytes compared to wild-type astrocytes. It has also been recently shown that human motor neurons differentiated from embryonic stem cells are susceptible to the same astrocytes isolated from the SOD1 G93A mouse model (Di Giorgio et al., 2008). Furthermore, human motor neurons derived from embryonic stem cells die in the presence of human fetal primary astrocytes overexpressing mutant SOD1 by lentivirus (Marchetto et al., 2008). These in vitro models support that mutant SOD1-expressing astrocytes are toxic to motor neurons regardless of the species and provide a way to study familial ALS utilizing human cells. While these results have been exciting, no consistent pathway has been implicated in these in vitro studies for causing motor neuron death; however, one common finding is that the toxicity is transferred through the media, suggesting a secreted factor may be responsible. Future studies will hopefully identify the specific factor(s) involved in this toxicity.

\subsection{ALS disease modeling using human-derived cells}

Development of in vitro ALS models provides another tool to investigate disease mechanisms and test therapeutics for ALS. Unfortunately, there has been a disconnect in the translation of drugs from rodent models of ALS to human clinical trials. While various drugs have shown promise in rodent models, there continues to be disappointment in clinical trials which may be a result of various factors including poor preclinical testing regimen, ineffective clinical design and delivery, or use of an animal model that does not accurately reflect human disease (Benatar, 2007). Indeed, most ALS models currently used for therapeutic testing are based on fALS caused by SOD1 mutations. Since fALS only accounts for $5-10 \%$ of ALS cases and SOD1 mutations are only present in $20 \%$ of these fALS patients, rodent ALS models may only represent $2 \%$ of all ALS cases. Thus, efforts have been focused on developing in vitro cell based models for sALS, representing the majority of the patient population. Human ALS-based in vitro models could be a helpful tool to identify 
drugs which modulate glial activity and be utilized as a complement to the mutant SOD1 mouse model to select more effective drugs for further clinical development.

Several methods can be employed to derive patient-specific glia for in vitro study. While it is difficult to isolate primary astrocytes or microglia from post-mortem tissue in large enough quantities, neural progenitor cells can be harvested from post-mortem brain and spinal cord tissue (Palmer et al., 2001). These human neural progenitor cells can be continuously expanded in vitro and differentiated into neurons, astrocytes, or oligodendrocytes for study. Recently, it has been shown that isolation of neural progenitor cells from post-mortem ALS spinal cord is feasible and astrocytes can be generated from these progenitors (HaidetPhillips et al., 2011). Astrocytes derived from a fALS patient harboring a SOD1 mutation were co-cultured with wild-type motor neurons and a 50\% increase in neuronal cell death was observed compared to co-culture with astrocytes from non-ALS controls, recapitulating evidence from the mutant SOD1 mouse model. However, it was also shown for the first time that astrocytes derived from sALS patients, which represent the majority of ALS patients, were similarly toxic to motor neurons in co-culture. The motor neuron death was shown to be triggered by conditioned astrocyte media, suggesting toxic secreted factors are responsible for motor neuron damage as seen in the mouse astrocyte co-culture studies. These results indicate a shared mechanism leading to motor neuron death between fALS and sALS through astrocyte-mediated toxicity and suggest therapies directed at astrocytes may be beneficial for both ALS populations.

In addition to neural progenitor cells, there are other stem cell sources which can be potentially used to derive patient-specific glial cells or motor neurons in vitro. With the development of induced pluripotent stem cell (iPSC) technology, many groups are also striving to create populations of neurons and astrocytes from iPSCs for disease modeling. iPSCs are pluripotent stem cells generated by reprogramming somatic cells through forced expression of specific pluripotency transcription factors. Like embryonic stem cells, iPSCs are characterized by an immense proliferative capacity and the ability to differentiate into all three germ lineages (endoderm, ectoderm, and mesoderm) which can eventually give rise to all tissues of the body (Yamanaka \& Blau, 2010). A variety of different cell types have now been reprogrammed into iPSCs including both mouse and human somatic cells (Okita et al., 2007; Park et al., 2008; Takahashi et al., 2007; Takahashi \& Yamanaka, 2006; Wernig et al., 2007; Yu et al., 2007). Importantly, protocols have also been developed for the differentiation of motor neurons, astrocytes, and oligodendrocytes from human iPSCs, which allow for in vitro ALS disease modeling (Czepiel et al., 2011; Dimos et al., 2008; Krencik et al., 2011; Liu et al., 2011).

Several groups have reprogrammed human fibroblasts from ALS patients into iPSCs and successfully differentiated motor neurons from these iPSCs (Boulting et al., 2011; Dimos et al., 2008). However, the major hurdle thus far has been demonstration of a disease-related phenotype in the iPSC-derived motor neurons. It may be necessary to either stress the iPSCderived motor neurons or co-culture with astrocytes also generated from ALS patient iPSCs in order to observe motor neuron damage. Still, it may be difficult to reproduce a relevant in vitro phenotype when working with diseases that are complex and likely multifactorial such as sALS. Another question posed by these experiments is whether or not reprogramming a cell and concordant epigenetic remodeling causes the loss of the ALS "signature". If sporadic ALS is triggered in part by epigenetic modifications, reprogramming may eliminate this epigenetic profile leaving essentially a "wild-type" cell. Therefore, 
comparisons between cells derived from ALS post-mortem tissues (not reprogrammed) and ALS-derived iPSCs may be crucial for dissecting these issues.

Although still in development, these in vitro-based ALS models provide a valuable platform for further mechanistic and therapeutic studies. Many of these models employ the use of $\mathrm{Hb} 9-\mathrm{GFP}$ reporter cell lines to generate motor neurons allowing for easy visualization of motor neuron survival over time in co-culture. With the reported ability to track motor neuron survival in real-time in a 96 well plate format (Haidet-Phillips et al., 2011), the development of high-throughput screens is foreseeable. Therapeutic compounds could be quickly screened for motor neuron protection against glial-cell mediated toxicity in this format. Additionally, one could envision genetic screens for modifiers of glial-cell derived motor neuron damage, leading to new therapeutic approaches or insights into disease mechanisms. Since there are currently no models for sALS, these in vitro-based systems utilizing either post-mortem neural progenitor or iPS-derived cells could provide a much needed novel platform for drug discovery. Although promising, some limitations do exist for in vitro modeling systems. For example, the time course for modeling motor neuron disease in vitro is short (days to weeks) whereas ALS is a late onset disorder which usually does not develop until 40-60 years of age. Additionally, the heterogeneity of ALS cases may pose another challenge, requiring a large number of both disease and control samples in order to identify relevant disease-related changes in vitro. Lastly, although in vitro modeling allows for dissection of cell-specific phenotypes, it will be important to evaluate any noticed changes in an in vivo context where many cell types interact and can influence disease.

\section{Therapeutic advances to target glial cells in ALS}

In recent years, much emphasis has been placed on the role of glial cells in mutant SOD1 mouse models and some of these findings have been recapitulated in vitro using human ALS patient-derived cells. Thus, many groups are devoting significant efforts to development of therapies directed at modulating glial cell activity. Indeed, glial cells have been suggested to affect both disease onset and progression in ALS mouse models. Since the majority of ALS patients are only diagnosed well after the onset of disease, therapies targeting disease progression by modification of glial cells may be beneficial in slowing symptomatic disease processes.

\subsection{Therapeutic agents to target astrocytes and microglia}

Currently, there is only one US Food and Drug Administration (FDA)-approved drug for the treatment of ALS and its therapeutic effects are hypothesized to derive from counteracting aberrant glutamate metabolism. Riluzole is an inhibitor of presynaptic glutamate release which may offset excitotoxicity seen in ALS. Riluzole has been confirmed to alter ALS disease survival in four independent clinical trials providing strong support for its therapeutic benefits (Miller et al., 2007). Unfortunately, riluzole only extends lifespan in ALS patients by an average of 3 months so efforts have focused on identifying other compounds which can counteract glutamate excitotoxicity. A variety of other drugs targeting glutamatergic pathways (talampanel, memantine, topiramate, lamotrigine, gabapentin, ONO-2506) have been evaluated in ALS patients, but the results have not suggested a benefit on disease course (Cudkowicz et al., 2003; de Carvalho et al., 2010; Miller et al., 2001; Ryberg et al., 2003; Zinman \& Cudkowicz, 2011). 
To identify new medications which may modulate glutamatergic pathways, an in vitro screening of over 1000 compounds already approved by the US Food and Drug Administration was completed (Rothstein et al., 2005). From this screen, $\beta$-lactam antibiotics were found to upregulate expression of the glutamate transporter, GLT1, and one of these antibiotics, ceftriaxone, was shown to significantly delay disease progression in the SOD1 G93A mouse model. Clinical trials testing intravenous ceftriaxone administration in ALS patients have already passed safety and tolerability stages and are currently in the final phase III of evaluation (Zinman \& Cudkowicz, 2011).

In contrast to specific targeting of glutamatergic pathways, a variety of anti-inflammatory agents have been tested with hopes to combat the extensive glial reaction observed in ALS patient brain and spinal cord. Prostaglandins are mediators of the inflammatory response that can be released in response to immune stimuli and production of prostaglandins is increased in the spinal cord of ALS patients (Kondo et al., 2002). Prostaglandin stimulation can be reduced by inhibiting cyclooxygenase 2 (COX2), an inducible enzyme involved in the synthesis of prostaglandins. Treatment of SOD1 G93A mice with COX2 inhibitors lowers prostaglandin levels and prolongs survival in these mice (Drachman et al., 2002; Klivenyi et al., 2004; Pompl et al., 2003). Unfortunately, the COX2 inhibitor, celecoxib, was ineffective at increasing survival in a clinical trial of ALS patients (Cudkowicz et al., 2006). However, prostaglandin E2 levels in the CSF of these patients was unaltered by celecoxib therapy indicating the dose may have been too low to reach therapeutic levels in the CNS (Aggarwal \& Cudkowicz, 2008).

Additional efforts to modulate the immune response in ALS have also been unsuccessful. The anti-microbial drug, minocycline, was shown to inhibit microglial activation and lengthen survival in mouse models of ALS (Kriz et al., 2002; Van Den Bosch et al., 2002; Zhu et al., 2002). Nonetheless, in a multicenter, randomized, phase III clinical trial of over 400 ALS patients, minocycline did not increase survival and in fact, was shown to worsen disease course in these patients (Gordon et al., 2007). The apparent divergence in results between preclinical animal studies and the clinical trial may have been due to the timing of minocycline treatment. When tested in animal models, minocycline was administered prior to symptomatic disease onset, whereas patients received the drug only after clinical onset of ALS. Indeed, a recent study showed that treatment of SOD1 G93A mice with minocycline administered after disease onset conferred no survival benefit and highlights the importance of a clinically-relevant testing regimen in ALS mouse studies (Keller et al., 2011). Compounds which modify neuroinflammation already present in the spinal cord, in contrast to preventing inflammation, may be more successful in the clinical setting.

\subsection{Stem cell therapies for ALS}

Because mounting data indicate that pathogenic glial cells actively contribute to motor neuron loss in ALS, one developing strategy is to replace the diseased glia with healthy cells which may alter the endogenous spinal cord environment and promote motor neuron survival. Transplantation of terminally differentiated glia to the CNS may pose technical difficulties since these cells are typically mature with limited proliferative and migratory capacity. Therefore, exploration of stem cells as a source for glial replacement has been sought after by many groups. 
Mutant SOD1-expressing microglia are key drivers of disease progression in mouse models of fALS. Since microglia are derived from the hematopoietic lineage, hematopoietic stem cells are one possible source for microglial cell replacement. When SOD1 mice lacking microglia are given bone marrow transplants from wild-type mice, the microglial cell population is reconstituted with healthy microglia and survival is prolonged (Beers et al., 2006). In translating this line of investigation to ALS patients, allogeneic peripheral blood hematopoietic stem cells were transplanted into ALS patients following full body irradiation (Appel et al., 2008). Although transplanted cells remarkably migrated to sites of motor neuron injury, no clinical change in disease was observed. It is possible that either the transplanted cells did not differentiate into microglia or that a large proportion of endogenous microglia survived post-irradiation which outnumbered healthy, transplanted stem cells. Trials are ongoing to similarly test intraparenchymal transplantation of hematopoietic stem cells to ALS patients (Deda et al., 2009), but results may be difficult to interpret based on the use of autologous (and potentially diseased) stem cells as a source instead of allogeneic (from a matched donor) derived stem cells. Further studies are needed in ALS rodent models to determine the optimal cell type, number, and delivery method for transplantation to establish a critical proof-of-principle for these paradigms.

Further efforts have focused on replacement of diseased astrocytes using various cell sources and delivery approaches. In contrast to microglia, astrocytes are derived from the neural lineage and can be differentiated from several stem cell sources including both glialrestricted precursors as well as neural stem and progenitor cells. Thus far, transplantation of neural progenitor cells to rodent ALS models has resulted in either a lack of differentiation in vivo (Klein et al., 2005; Suzuki et al., 2007) or differentiation to mostly neurons after neural stem cell transplantation, but not to astrocytes (Xu et al., 2009; Xu et al., 2011).

In contrast, glial-restricted precursors are lineage-restricted and can only become astrocytes or oligodendrocytes. Transplantation of glial-restricted precursors to the cervical spinal cord of SOD1 G93A rats led to extensive differentiation of grafted cells into astrocytes $(>85 \%$ of transplanted cells) which reduced significant motor neuron loss (Lepore et al., 2008b). The graft-derived astrocytes expressed increased levels of GLT1 in comparison to endogenous diseased astrocytes, which likely played a major role in protecting motor neurons. Importantly, rats receiving transplants also survived longer and showed preserved forelimb grip strength and respiratory function, attributable to the focal delivery of glial-restricted precursor cells to the cervical region of the spinal cord. This work provides a proof-ofprinciple for astrocyte replacement in ALS and sets the stage for future clinical trials testing transplantation of human glial-restricted precursors in ALS patients. Questions still remain as to whether human glial-restricted precursors will survive and differentiate after transplantation into humans and which spinal cord regions are most practical for targeting in ALS patients.

With the advancement of stem cell technology, astrocytes as well as neural progenitors (and possibly glial-restricted precursors) can now be derived from human iPS cells. This novel stem cell source provides another option for glial-cell replacement therapies since iPS cells have immense expansive abilities in vitro. A major potential advantage to iPS cells is that these cells can be derived directly from a living patient. In theory, use of autologous iPS cells for transplantation therapies may lessen worries of graft rejection and obviate the need for continued immunosuppressive therapy. However, one study testing this paradigm documented rejection of mouse iPS cells after transplantation to an autologous recipient, 
cautioning that transplantation of these cells may be more complex than originally thought (Zhao et al., 2011). Another issue is whether stem cells derived from ALS patients carry the disease phenotype. If so, any cells differentiated from the patient iPS cells may not provide the desired therapeutic benefit. In cases where there exists a disease-associated mutation such as SOD1, ex-vivo genetic correction of the mutation through homologous recombination, viral vectors, or zinc finger technology may be possible (Amabile \& Meissner, 2009). However, most ALS patients have no identified genetic mutation responsible for the disease. Additionally, there remain many unresolved challenges with iPS cell therapy such as obtaining efficient differentiation of the iPS cells to the desired cell population, purifying a safe and non-tumorgenic population for transplantation, and optimizing delivery methods for transplantation of the iPS-derived cells back to the patient. In addition to benefits derived from replacing diseased glia, transplanted populations of stem cells may also be used to deliver therapeutics to the brain and spinal cord. Stem cells can be genetically modified in vitro by transduction with viral vectors which can integrate into the genome and stably express therapeutic genes long-term. Since many therapeutic proteins have short half-lives after direct injection, genetically modified stem cells transplanted to the brain or spinal cord would allow for continuous production of the desired protein at the site of neurodegeneration, serving as "therapeutic pumps" in vivo. For example, human neural progenitor cells transduced with a lentivirus expressing glialderived neurotrophic factor (GDNF) and transplanted to the ALS rat spinal cord can produce GDNF in vivo and protect motor neurons (Klein et al., 2005; Suzuki et al., 2007). One could envision using stem cells to deliver not only neuroprotective factors, but also therapies to modulate the glial environment such as anti-inflammatory proteins or antiglutamatergic agents.

\subsection{Gene-targeted therapies for ALS}

The mechanisms leading to motor neuron death in ALS are still unclear; however, it is generally agreed in the field that in cases of SOD1 fALS, the mutant SOD1 protein harbors a toxic gain-of-function and reduction of mutant SOD1 is likely to be beneficial in these patients. Additionally, several studies have implicated a pathogenic role for wild-type SOD1 in cases of sALS (Bosco et al., 2010; Gruzman et al., 2007), including a potential role in glial cells (HaidetPhillips et al., 2011). Therefore, therapies aimed at reducing SOD1 levels may potentially be applicable for not only SOD1 fALS patients, but for other ALS patient populations as well.

A variety of approaches have been attempted to reduce SOD1 levels in rodent models of ALS. RNA interference (RNAi) is a post-transcriptional gene-silencing mechanism initiated by small interfering RNAs (siRNA) which are double-stranded pieces of RNA 21-23 nucleotides in length (Sah \& Aronin, 2011). Within the cytoplasm, the siRNA gets recognized and directed to the RNA-induced silencing complex. The silencing complex then uses the sequence-specific information on the siRNA to initiate degradation of endogenous complementary mRNA sequences, leading to subsequent gene silencing. Targeted siRNA can be exogenously delivered to a cell although naked siRNA is instable with a relatively short half life (Sah \& Aronin, 2011). Alternatively, viral vectors can be used to continuously transcribe RNA containing short complementary sequences (Miller et al., 2008). These complementary sequences can bind, leading to duplex hairpin formation (short hairpin RNA or shRNA). Once transcribed, the shRNA gets recognized by the cellular machinery and cleaved by the Dicer enzyme to produce short, double-stranded siRNA sequences. 
Sequences of siRNA targeted against SOD1 mRNA have been designed to reduce levels of the mutant SOD1 protein. Similar to many small molecule therapies, siRNA does not cross the blood-brain-barrier, creating challenges for delivery to the CNS (Sah \& Aronin, 2011). Viral-mediated delivery of SOD1 shRNA has been attempted in rodent models of ALS with successful knockdown of SOD1 levels by both lentivirus and adeno-associated virus (AAV) (Miller et al., 2005; Ralph et al., 2005; Towne et al., 2011). However, these studies have targeted only motor neurons, transduced after retrograde transport from muscles injected with the virus. These strategies were unsuccessful in slowing disease progression, most likely due to the fact that motor neurons were solely targeted, although glial cells play a significant role in the disease process.

Other approaches have strived to target both motor neurons and glial cells with SOD1 shRNA. Intraparenchymal injection to the lumbar spinal cord of a lentivirus encoding SOD1 shRNA was shown to reduce SOD1 levels and retard disease onset and progression in the SOD1 G93A mouse (Raoul et al., 2005). Yet, the vast anatomical distribution of diseased cells throughout the motor cortex, brain stem and spinal cord pose a hurdle for direct injection of viral therapy with limited diffusive capacity. A novel version of AAV, AAV serotype 9, has recently shown potential for extensive targeting of CNS tissues (Foust et al., 2009). In this study, AAV9 was able to cross the blood-brain-barrier after vascular delivery and transduce over $60 \%$ of astrocytes in the brain and spinal cord. Additional evaluation in non-human primates verified that AAV9 is capable of efficiently targeting both motor neurons and glia in the brain and spinal cord after vascular delivery to a large species (Bevan et al., 2011). Use of this virus to deliver SOD1 shRNA is conceivable, although steps may be needed to target viral expression away from peripheral organs and only to CNS tissues.

Instead of using a viral vector to deliver shRNA sequences, others have sought to create more stable siRNA for direct delivery through chemically modifying the siRNA (Wang et al., 2008). Intrathecal infusion of chemically-modified SOD1 siRNA using an osmotic pump generated a 15\% knockdown in SOD1 protein levels and a modest therapeutic effect in the SOD1 G93A mice. One potential advantage to infusion of naked, stabilized siRNA over viral delivery is the ability to halt the treatment at any time following adverse effects. Therefore, this type of RNAi therapy seems promising at least for treatment of ALS patients with SOD1 mutations.

A similar approach to RNAi therapy involves the use of antisense oligonucleotides to enact post-transcriptional gene silencing (Sah \& Aronin, 2011). Antisense oligonucleotides are short (15-25 nucleotides) single stranded pieces of synthetic DNA which can bind to complementary mRNA sequences in the cytoplasm. Once bound, these DNA-mRNA complexes are targeted for degradation by the enzyme RNase H. Additionally, translation of mRNA bound by antisense oligonucleotides can be physically blocked, leading to further gene silencing for targeted mRNA sequences. Antisense oligonucleotides are generally more stable than naked siRNA with a half life of 2-6 weeks after delivery to the mouse and monkey CNS (Sah \& Aronin, 2011). Like siRNA, antisense oligonucleotides can be absorbed by both neurons and glia to execute gene silencing. Sequence specific targeting of antisense oligonucleotides to SOD1 mRNA has been attainable, with a 50\% reduction in SOD1 protein levels in the brain and spinal cord of SOD1 G93A rats infused for 28 days with antisense oligonucleotides into the right ventricle (Smith et al., 2006). The rats treated with SOD1 antisense oligonucleotides showed a slowed disease progression and this same SOD1 antisense oligonucleotide was demonstrated to lower SOD1 levels in fibroblasts isolated 
from an ALS patient. A phase I clinical trial has been initiated in fALS patients with SOD1 mutations testing intrathecal infusion of this same antisense oligonucleotide against SOD1. This dose-escalation trial will evaluate safety, tolerability, and pharmacokinetics in patients treated with antisense oligonucleotide infusion for 12 hours. If proven safe, this strategy holds considerable promise to treat SOD1 fALS patients.

While a great deal of progress has been made in the development of anti-SOD1 therapies, additional work needs to be focused on advancing novel treatments for non-SOD1 ALS patient populations. As additional genetic mutations are linked to ALS, these genes might present new targets for gene-based therapeutic approaches. However, in the case of TDP43 and FUS mutations, a great deal of basic research is still required to evaluate whether a lossof-function or gain-of-function mechanism is responsible for disease caused by these mutations and whether glial cells are also a target in these cases. Until these crucial questions are answered, it will be difficult to develop RNAi or gene therapy treatments for these patients. Efforts to reach a broad ALS patient population may benefit most from the design of therapies which interfere with downstream mechanisms prevalent in most patients, such as glial-mediated glutamate excitotoxicity or neuroinflammation. Many of the siRNA and antisense oligonucleotide approaches can be amenable to inhibit potentially damaging genes involved in these glial responses. Additionally, viral vectors have been developed that can deliver gene therapies to glial cells in the CNS, allowing for potential immune modulation. With increasingly innovative developments in RNAi and gene therapy, the door is open for novel gene-based therapies to alter the ALS disease process.

\section{Conclusion}

The field of ALS research has progressed significantly in recent years with the identification of glial cells as an active contributor to the disease process. Specifically, astrocytes and microglia have been recognized as glial cell types which undeniably influence survival in rodent models of ALS. Efforts are underway to test therapies aimed at modifying the glial cell population in hopes of slowing ALS disease progression and extending patient survival. While rodent models of ALS have been key in revealing glial cells as a disease contributor in SOD1 fALS, it still remains to be determined to what extent glial cells are involved in disease processes in other patient populations. New genes have been recently linked ALS including TDP43 and FUS, suggesting a possible role for RNA metabolism in disease pathogenesis. Creation of both rodent and in vitro models mimicking these forms of ALS is underway and will hopefully reveal whether glial cells are also a target in patients harboring these mutations.

Although glial cell targets have been identified, much work remains to elucidate the mechanisms behind their neural toxicity. Several groups have been able to model the glialmotor neuron interface in vitro using unique stem-cell based models to study the effects of diseased glia on motor neurons. While these studies have yet to identify relevant mechanisms involved in glial-mediated toxicity, in vitro models present the opportunity to study human patient-derived glial cells from both fALS and sALS patients. With the development of iPSC technology, there exists potential to study patient-specific glial cells and evaluate therapies in a high-throughput fashion.

Discovery of mechanisms involved in glial pathogenicity will likely lead to the development of promising therapeutic interventions. Detection of additional pathways of importance will hopefully shed light on new compounds which may be capable of targeting glial- 
mediated motor neuron damage. Furthermore, stem cell and gene-based therapies have reached evaluation in clinical trials, creating excitement and optimism in the field. As new knowledge of disease mechanisms arises, there is great hope for novel interventions to target glial cells and significantly change the ALS disease course.

\section{References}

Aggarwal, S. \& Cudkowicz, M., (2008). ALS drug development: reflections from the past and a way forward. Neurotherapeutics. Vol. 5, No. 4, pp. 516-27.

Almer, G., Vukosavic, S., Romero, N. \& Przedborski, S., (1999). Inducible nitric oxide synthase up-regulation in a transgenic mouse model of familial amyotrophic lateral sclerosis. J Neurochem. Vol. 72, No. 6, pp. 2415-25.

Amabile, G. \& Meissner, A., (2009). Induced pluripotent stem cells: current progress and potential for regenerative medicine. Trends Mol Med. Vol. 15, No. 2, pp. 59-68.

Appel, S.H., Engelhardt, J.I., Henkel, J.S., Siklos, L., Beers, D.R., Yen, A.A., Simpson, E.P., Luo, Y., Carrum, G., Heslop, H.E., Brenner, M.K. \& Popat, U., (2008). Hematopoietic stem cell transplantation in patients with sporadic amyotrophic lateral sclerosis. Neurology. Vol. 71, No. 17, pp. 1326-34.

Beers, D.R., Henkel, J.S., Xiao, Q., Zhao, W., Wang, J., Yen, A.A., Siklos, L., McKercher, S.R. \& Appel, S.H., (2006). Wild-type microglia extend survival in PU.1 knockout mice with familial amyotrophic lateral sclerosis. Proc Natl Acad Sci U S A. Vol. 103, No. 43, pp. 16021-6.

Beers, D.R., Henkel, J.S., Zhao, W., Wang, J., Huang, A., Wen, S., Liao, B. \& Appel, S.H., (2011). Endogenous regulatory $\mathrm{T}$ lymphocytes ameliorate amyotrophic lateral sclerosis in mice and correlate with disease progression in patients with amyotrophic lateral sclerosis. Brain. Vol. 134, No. Pt 5, pp. 1293-314.

Benatar, M., (2007). Lost in translation: treatment trials in the SOD1 mouse and in human ALS. Neurobiol Dis. Vol. 26, No. 1, pp. 1-13.

Bendotti, C., Tortarolo, M., Suchak, S.K., Calvaresi, N., Carvelli, L., Bastone, A., Rizzi, M., Rattray, M. \& Mennini, T., (2001). Transgenic SOD1 G93A mice develop reduced GLT-1 in spinal cord without alterations in cerebrospinal fluid glutamate levels. $J$ Neurochem. Vol. 79, No. 4, pp. 737-46.

Bevan, A.K., Duque, S., Foust, K.D., Morales, P.R., Braun, L., Schmelzer, L., Chan, C.M., McCrate, M., Chicoine, L.G., Coley, B.D., Porensky, P.N., Kolb, S.J., Mendell, J.R., Burghes, A.H. \& Kaspar, B.K., (2011). Systemic Gene Delivery in Large Species for Targeting Spinal Cord, Brain, and Peripheral Tissues for Pediatric Disorders. Mol Ther. Vol., No., pp.

Boillee, S., Vande Velde, C. \& Cleveland, D.W., (2006a). ALS: a disease of motor neurons and their nonneuronal neighbors. Neuron. Vol. 52, No. 1, pp. 39-59.

Boillee, S., Yamanaka, K., Lobsiger, C.S., Copeland, N.G., Jenkins, N.A., Kassiotis, G., Kollias, G. \& Cleveland, D.W., (2006b). Onset and Progression in Inherited ALS Determined by Motor Neurons and Microglia. Science. Vol. 312, No. 5778, pp. 138992.

Bosco, D.A., Morfini, G., Karabacak, N.M., Song, Y., Gros-Louis, F., Pasinelli, P., Goolsby, H., Fontaine, B.A., Lemay, N., McKenna-Yasek, D., Frosch, M.P., Agar, J.N., Julien, J.P., Brady, S.T. \& Brown, R.H., Jr., (2010). Wild-type and mutant SOD1 share an aberrant conformation and a common pathogenic pathway in ALS. Nat Neurosci. Vol. 13, No. 11, pp. 1396-403. 
Boulting, G.L., Kiskinis, E., Croft, G.F., Amoroso, M.W., Oakley, D.H., Wainger, B.J., Williams, D.J., Kahler, D.J., Yamaki, M., Davidow, L., Rodolfa, C.T., Dimos, J.T., Mikkilineni, S., MacDermott, A.B., Woolf, C.J., Henderson, C.E., Wichterle, H. \& Eggan, K., (2011). A functionally characterized test set of human induced pluripotent stem cells. Nat Biotechnol. Vol. 29, No. 3, pp. 279-86.

Bristol, L.A. \& Rothstein, J.D., (1996). Glutamate transporter gene expression in amyotrophic lateral sclerosis motor cortex. Ann Neurol. Vol. 39, No. 5, pp. 676-9.

Bruijn, L.I., Becher, M.W., Lee, M.K., Anderson, K.L., Jenkins, N.A., Copeland, N.G., Sisodia, S.S., Rothstein, J.D., Borchelt, D.R., Price, D.L. \& Cleveland, D.W., (1997). ALSlinked SOD1 mutant G85R mediates damage to astrocytes and promotes rapidly progressive disease with SOD1-containing inclusions. Neuron. Vol. 18, No. 2, pp. 327-38.

Bruijn, L.I., Houseweart, M.K., Kato, S., Anderson, K.L., Anderson, S.D., Ohama, E., Reaume, A.G., Scott, R.W. \& Cleveland, D.W., (1998). Aggregation and motor neuron toxicity of an ALS-linked SOD1 mutant independent from wild-type SOD1. Science. Vol. 281, No. 5384, pp. 1851-4.

Chiu, A.Y., Zhai, P., Dal Canto, M.C., Peters, T.M., Kwon, Y.W., Prattis, S.M. \& Gurney, M.E., (1995). Age-dependent penetrance of disease in a transgenic mouse model of familial amyotrophic lateral sclerosis. Mol Cell Neurosci. Vol. 6, No. 4, pp. 349-62.

Chiu, I.M., Chen, A., Zheng, Y., Kosaras, B., Tsiftsoglou, S.A., Vartanian, T.K., Brown, R.H., Jr. \& Carroll, M.C., (2008). T lymphocytes potentiate endogenous neuroprotective inflammation in a mouse model of ALS. Proc Natl Acad Sci U S A. Vol. 105, No. 46, pp. 17913-8.

Clement, A.M., Nguyen, M.D., Roberts, E.A., Garcia, M.L., Boillee, S., Rule, M., McMahon, A.P., Doucette, W., Siwek, D., Ferrante, R.J., Brown, R.H., Jr., Julien, J.P., Goldstein, L.S. \& Cleveland, D.W., (2003). Wild-type nonneuronal cells extend survival of SOD1 mutant motor neurons in ALS mice. Science. Vol. 302, No. 5642, pp. 113-7.

Cohen, T.J., Lee, V.M. \& Trojanowski, J.Q., (2011). TDP-43 functions and pathogenic mechanisms implicated in TDP-43 proteinopathies. Trends Mol Med. Vol., No., pp.

Cudkowicz, M.E., Shefner, J.M., Schoenfeld, D.A., Brown, R.H., Jr., Johnson, H., Qureshi, M., Jacobs, M., Rothstein, J.D., Appel, S.H., Pascuzzi, R.M., Heiman-Patterson, T.D., Donofrio, P.D., David, W.S., Russell, J.A., Tandan, R., Pioro, E.P., Felice, K.J., Rosenfeld, J., Mandler, R.N., Sachs, G.M., Bradley, W.G., Raynor, E.M., Baquis, G.D., Belsh, J.M., Novella, S., Goldstein, J. \& Hulihan, J., (2003). A randomized, placebo-controlled trial of topiramate in amyotrophic lateral sclerosis. Neurology. Vol. 61, No. 4, pp. 456-64.

Cudkowicz, M.E., Shefner, J.M., Schoenfeld, D.A., Zhang, H., Andreasson, K.I., Rothstein, J.D. \& Drachman, D.B., (2006). Trial of celecoxib in amyotrophic lateral sclerosis. Ann Neurol. Vol. 60, No. 1, pp. 22-31.

Czepiel, M., Balasubramaniyan, V., Schaafsma, W., Stancic, M., Mikkers, H., Huisman, C., Boddeke, E. \& Copray, S., (2011). Differentiation of induced pluripotent stem cells into functional oligodendrocytes. Glia. Vol. 59, No. 6, pp. 882-92.

de Carvalho, M., Pinto, S., Costa, J., Evangelista, T., Ohana, B. \& Pinto, A., (2010). A randomized, placebo-controlled trial of memantine for functional disability in amyotrophic lateral sclerosis. Amyotroph Lateral Scler. Vol. 11, No. 5, pp. 456-60.

Deda, H., Inci, M.C., Kurekci, A.E., Sav, A., Kayihan, K., Ozgun, E., Ustunsoy, G.E. \& Kocabay, S., (2009). Treatment of amyotrophic lateral sclerosis patients by 
autologous bone marrow-derived hematopoietic stem cell transplantation: a 1-year follow-up. Cytotherapy. Vol. 11, No. 1, pp. 18-25.

Di Giorgio, F.P., Carrasco, M.A., Siao, M.C., Maniatis, T. \& Eggan, K., (2007). Non-cell autonomous effect of glia on motor neurons in an embryonic stem cell-based ALS model. Nat Neurosci. Vol. 10, No. 5, pp. 608-614.

Di Giorgio, F.P., Boulting, G.L., Bobrowicz, S. \& Eggan, K.C., (2008). Human embryonic stem cell-derived motor neurons are sensitive to the toxic effect of glial cells carrying an ALS-causing mutation. Cell Stem Cell. Vol. 3, No. 6, pp. 637-48.

Dimos, J.T., Rodolfa, K.T., Niakan, K.K., Weisenthal, L.M., Mitsumoto, H., Chung, W., Croft, G.F., Saphier, G., Leibel, R., Goland, R., Wichterle, H., Henderson, C.E. \& Eggan, K., (2008). Induced pluripotent stem cells generated from patients with ALS can be differentiated into motor neurons. Science. Vol. 321, No. 5893, pp. 1218-21.

Dodge, J.C., Haidet, A.M., Yang, W., Passini, M.A., Hester, M., Clarke, J., Roskelley, E.M., Treleaven, C.M., Rizo, L., Martin, H., Kim, S.H., Kaspar, R., Taksir, T.V., Griffiths, D.A., Cheng, S.H., Shihabuddin, L.S. \& Kaspar, B.K., (2008). Delivery of AAV-IGF-1 to the CNS extends survival in ALS mice through modification of aberrant glial cell activity. Mol Ther. Vol. 16, No. 6, pp. 1056-64.

Drachman, D.B., Frank, K., Dykes-Hoberg, M., Teismann, P., Almer, G., Przedborski, S. \& Rothstein, J.D., (2002). Cyclooxygenase 2 inhibition protects motor neurons and prolongs survival in a transgenic mouse model of ALS. Ann Neurol. Vol. 52, No. 6, pp. 771-8.

Foust, K.D., Nurre, E., Montgomery, C.L., Hernandez, A., Chan, C.M. \& Kaspar, B.K., (2009). Intravascular AAV9 preferentially targets neonatal neurons and adult astrocytes. Nat Biotechnol. Vol. 27, No. 1, pp. 59-65.

Gordon, P.H., Moore, D.H., Miller, R.G., Florence, J.M., Verheijde, J.L., Doorish, C., Hilton, J.F., Spitalny, G.M., MacArthur, R.B., Mitsumoto, H., Neville, H.E., Boylan, K., Mozaffar, T., Belsh, J.M., Ravits, J., Bedlack, R.S., Graves, M.C., McCluskey, L.F., Barohn, R.J. \& Tandan, R., (2007). Efficacy of minocycline in patients with amyotrophic lateral sclerosis: a phase III randomised trial. Lancet Neurol. Vol. 6, No. 12, pp. $1045-53$.

Gruzman, A., Wood, W.L., Alpert, E., Prasad, M.D., Miller, R.G., Rothstein, J.D., Bowser, R., Hamilton, R., Wood, T.D., Cleveland, D.W., Lingappa, V.R. \& Liu, J., (2007). Common molecular signature in SOD1 for both sporadic and familial amyotrophic lateral sclerosis. Proc Natl Acad Sci U S A. Vol. 104, No. 30, pp. 12524-9.

Gurney, M.E., Pu, H., Chiu, A.Y., Dal Canto, M.C., Polchow, C.Y., Alexander, D.D., Caliendo, J., Hentati, A., Kwon, Y.W., Deng, H.X. \& et al., (1994). Motor neuron degeneration in mice that express a human $\mathrm{Cu}, \mathrm{Zn}$ superoxide dismutase mutation. Science. Vol. 264, No. 5166, pp. 1772-5.

Haidet-Phillips, A.M., Hester, M.E., Miranda, C.J., Meyer, K., Braun, L., Frakes, A., Song, S., Likhite, S., Murtha, M.J., Foust, K.D., Rao, M., Eagle, A., Kammesheidt, A., Christensen, A., Mendell, J.R., Burghes, A.H. \& Kaspar, B.K., (2011). Astrocytes from familial and sporadic ALS patients are toxic to motor neurons. Nat Biotechnol. Vol., No., pp.

Henkel, J.S., Beers, D.R., Zhao, W. \& Appel, S.H., (2009). Microglia in ALS: The Good, The Bad, and The Resting. J Neuroimmune Pharmacol. Vol., No., pp.

Hensley, K., Fedynyshyn, J., Ferrell, S., Floyd, R.A., Gordon, B., Grammas, P., Hamdheydari, L., Mhatre, M., Mou, S., Pye, Q.N., Stewart, C., West, M., West, S. \& Williamson, K.S., (2003). Message and protein-level elevation of tumor necrosis factor alpha 
(TNF alpha) and TNF alpha-modulating cytokines in spinal cords of the G93ASOD1 mouse model for amyotrophic lateral sclerosis. Neurobiol Dis. Vol. 14, No. 1, pp. 74-80.

Huang, C., Zhou, H., Tong, J., Chen, H., Liu, Y.J., Wang, D., Wei, X. \& Xia, X.G., (2011). FUS transgenic rats develop the phenotypes of amyotrophic lateral sclerosis and frontotemporal lobar degeneration. PLoS Genet. Vol. 7, No. 3, pp. e1002011.

Jaarsma, D., Teuling, E., Haasdijk, E.D., De Zeeuw, C.I. \& Hoogenraad, C.C., (2008). Neuronspecific expression of mutant superoxide dismutase is sufficient to induce amyotrophic lateral sclerosis in transgenic mice. J Neurosci. Vol. 28, No. 9, pp. 2075-88.

Kabashi, E., Valdmanis, P.N., Dion, P., Spiegelman, D., McConkey, B.J., Vande Velde, C., Bouchard, J.P., Lacomblez, L., Pochigaeva, K., Salachas, F., Pradat, P.F., Camu, W., Meininger, V., Dupre, N. \& Rouleau, G.A., (2008). TARDBP mutations in individuals with sporadic and familial amyotrophic lateral sclerosis. Nat Genet. Vol. 40, No. 5, pp. 572-4.

Kang, S.H., Fukaya, M., Yang, J.K., Rothstein, J.D. \& Bergles, D.E., (2010). NG2+ CNS glial progenitors remain committed to the oligodendrocyte lineage in postnatal life and following neurodegeneration. Neuron. Vol. 68, No. 4, pp. 668-81.

Keller, A.F., Gravel, M. \& Kriz, J., (2011). Treatment with minocycline after disease onset alters astrocyte reactivity and increases microgliosis in SOD1 mutant mice. Exp Neurol. Vol. 228, No. 1, pp. 69-79.

Klein, S.M., Behrstock, S., McHugh, J., Hoffmann, K., Wallace, K., Suzuki, M., Aebischer, P. \& Svendsen, C.N., (2005). GDNF delivery using human neural progenitor cells in a rat model of ALS. Hum Gene Ther. Vol. 16, No. 4, pp. 509-21.

Klivenyi, P., Kiaei, M., Gardian, G., Calingasan, N.Y. \& Beal, M.F., (2004). Additive neuroprotective effects of creatine and cyclooxygenase 2 inhibitors in a transgenic mouse model of amyotrophic lateral sclerosis. J Neurochem. Vol. 88, No. 3, pp. 576-82.

Kondo, M., Shibata, T., Kumagai, T., Osawa, T., Shibata, N., Kobayashi, M., Sasaki, S., Iwata, M., Noguchi, N. \& Uchida, K., (2002). 15-Deoxy-Delta(12,14)-prostaglandin J(2): the endogenous electrophile that induces neuronal apoptosis. Proc Natl Acad Sci U S A. Vol. 99, No. 11, pp. 7367-72.

Krencik, R., Weick, J.P., Liu, Y., Zhang, Z.J. \& Zhang, S.C., (2011). Specification of transplantable astroglial subtypes from human pluripotent stem cells. Nat Biotechnol. Vol. 29, No. 6, pp. 528-34.

Kriz, J., Nguyen, M.D. \& Julien, J.P., (2002). Minocycline slows disease progression in a mouse model of amyotrophic lateral sclerosis. Neurobiol Dis. Vol. 10, No. 3, pp. 268-78.

Kwiatkowski, T.J., Jr., Bosco, D.A., Leclerc, A.L., Tamrazian, E., Vanderburg, C.R., Russ, C., Davis, A., Gilchrist, J., Kasarskis, E.J., Munsat, T., Valdmanis, P., Rouleau, G.A., Hosler, B.A., Cortelli, P., de Jong, P.J., Yoshinaga, Y., Haines, J.L., Pericak-Vance, M.A., Yan, J., Ticozzi, N., Siddique, T., McKenna-Yasek, D., Sapp, P.C., Horvitz, H.R., Landers, J.E. \& Brown, R.H., Jr., (2009). Mutations in the FUS/TLS gene on chromosome 16 cause familial amyotrophic lateral sclerosis. Science. Vol. 323, No. 5918, pp. 1205-8.

Lepore, A.C., Dejea, C., Carmen, J., Rauck, B., Kerr, D.A., Sofroniew, M.V. \& Maragakis, N.J., (2008a). Selective ablation of proliferating astrocytes does not affect disease outcome in either acute or chronic models of motor neuron degeneration. Exp Neurol. Vol. 211, No. 2, pp. 423-32. 
Lepore, A.C., Rauck, B., Dejea, C., Pardo, A.C., Rao, M.S., Rothstein, J.D. \& Maragakis, N.J., (2008b). Focal transplantation-based astrocyte replacement is neuroprotective in a model of motor neuron disease. Nat Neurosci. Vol. 11, No. 11, pp. 1294-301.

Lino, M.M., Schneider, C. \& Caroni, P., (2002). Accumulation of SOD1 mutants in postnatal motoneurons does not cause motoneuron pathology or motoneuron disease. J Neurosci. Vol. 22, No. 12, pp. 4825-32.

Liu, Y., Jiang, P. \& Deng, W., (2011). OLIG gene targeting in human pluripotent stem cells for motor neuron and oligodendrocyte differentiation. Nat Protoc. Vol. 6, No. 5, pp. 640-55.

Lobsiger, C.S., Boillee, S., McAlonis-Downes, M., Khan, A.M., Feltri, M.L., Yamanaka, K. \& Cleveland, D.W., (2009). Schwann cells expressing dismutase active mutant SOD1 unexpectedly slow disease progression in ALS mice. Proc Natl Acad Sci U S A. Vol. 106, No. 11, pp. 4465-70.

Mackenzie, I.R., Bigio, E.H., Ince, P.G., Geser, F., Neumann, M., Cairns, N.J., Kwong, L.K., Forman, M.S., Ravits, J., Stewart, H., Eisen, A., McClusky, L., Kretzschmar, H.A., Monoranu, C.M., Highley, J.R., Kirby, J., Siddique, T., Shaw, P.J., Lee, V.M. \& Trojanowski, J.Q., (2007). Pathological TDP-43 distinguishes sporadic amyotrophic lateral sclerosis from amyotrophic lateral sclerosis with SOD1 mutations. Ann Neurol. Vol. 61, No. 5, pp. 427-34.

Mackenzie, I.R., Rademakers, R. \& Neumann, M., (2010). TDP-43 and FUS in amyotrophic lateral sclerosis and frontotemporal dementia. Lancet Neurol. Vol. 9, No. 10, pp. 995-1007.

Magnus, T., Carmen, J., Deleon, J., Xue, H., Pardo, A.C., Lepore, A.C., Mattson, M.P., Rao, M.S. \& Maragakis, N.J., (2008). Adult glial precursor proliferation in mutant SOD1G93A mice. Glia. Vol. 56, No. 2, pp. 200-8.

Maragakis, N.J. \& Rothstein, J.D., (2006). Mechanisms of Disease: astrocytes in neurodegenerative disease. Nat Clin Pract Neurol. Vol. 2, No. 12, pp. 679-89.

Marchetto, M.C., Muotri, A.R., Mu, Y., Smith, A.M., Cezar, G.G. \& Gage, F.H., (2008). Noncell-autonomous effect of human SOD1 G37R astrocytes on motor neurons derived from human embryonic stem cells. Cell Stem Cell. Vol. 3, No. 6, pp. 649-57.

Miller, R.G., Moore, D.H., 2nd, Gelinas, D.F., Dronsky, V., Mendoza, M., Barohn, R.J., Bryan, W., Ravits, J., Yuen, E., Neville, H., Ringel, S., Bromberg, M., Petajan, J., Amato, A.A., Jackson, C., Johnson, W., Mandler, R., Bosch, P., Smith, B., Graves, M., Ross, M., Sorenson, E.J., Kelkar, P., Parry, G. \& Olney, R., (2001). Phase III randomized trial of gabapentin in patients with amyotrophic lateral sclerosis. Neurology. Vol. 56, No. 7, pp. 843-8.

Miller, R.G., Mitchell, J.D., Lyon, M. \& Moore, D.H., (2007). Riluzole for amyotrophic lateral sclerosis (ALS)/motor neuron disease (MND). Cochrane Database Syst Rev. Vol., No. 1, pp. CD001447.

Miller, T.M., Kaspar, B.K., Kops, G.J., Yamanaka, K., Christian, L.J., Gage, F.H. \& Cleveland, D.W., (2005). Virus-delivered small RNA silencing sustains strength in amyotrophic lateral sclerosis. Ann Neurol. Vol. 57, No. 5, pp. 773-6.

Miller, T.M., Smith, R.A., Kordasiewicz, H. \& Kaspar, B.K., (2008). Gene-targeted therapies for the central nervous system. Arch Neurol. Vol. 65, No. 4, pp. 447-51.

Nagai, M., Re, D.B., Nagata, T., Chalazonitis, A., Jessell, T.M., Wichterle, H. \& Przedborski, S., (2007). Astrocytes expressing ALS-linked mutated SOD1 release factors selectively toxic to motor neurons. Nat Neurosci. Vol. 10, No. 5, pp. 615-622.

Neumann, M., Sampathu, D.M., Kwong, L.K., Truax, A.C., Micsenyi, M.C., Chou, T.T., Bruce, J., Schuck, T., Grossman, M., Clark, C.M., McCluskey, L.F., Miller, B.L., Masliah, E., Mackenzie, I.R., Feldman, H., Feiden, W., Kretzschmar, H.A., Trojanowski, J.Q. \& Lee, 
V.M., (2006). Ubiquitinated TDP-43 in frontotemporal lobar degeneration and amyotrophic lateral sclerosis. Science. Vol. 314, No. 5796, pp. 130-3.

Nguyen, M.D., Julien, J.P. \& Rivest, S., (2001). Induction of proinflammatory molecules in mice with amyotrophic lateral sclerosis: no requirement for proapoptotic interleukin-1beta in neurodegeneration. Ann Neurol. Vol. 50, No. 5, pp. 630-9.

Okita, K., Ichisaka, T. \& Yamanaka, S., (2007). Generation of germline-competent induced pluripotent stem cells. Nature. Vol. 448, No. 7151, pp. 313-7.

Palmer, T.D., Schwartz, P.H., Taupin, P., Kaspar, B., Stein, S.A. \& Gage, F.H., (2001). Cell culture. Progenitor cells from human brain after death. Nature. Vol. 411, No. 6833, pp. 42-3.

Park, I.H., Zhao, R., West, J.A., Yabuuchi, A., Huo, H., Ince, T.A., Lerou, P.H., Lensch, M.W. \& Daley, G.Q., (2008). Reprogramming of human somatic cells to pluripotency with defined factors. Nature. Vol. 451, No. 7175, pp. 141-6.

Perrie, W.T., Lee, G.T., Curtis, E.M., Sparke, J., Buller, J.R. \& Rossi, M.L., (1993). Changes in the myelinated axons of femoral nerve in amyotrophic lateral sclerosis. J Neural Transm Suppl. Vol. 39, No., pp. 223-33.

Pompl, P.N., Ho, L., Bianchi, M., McManus, T., Qin, W. \& Pasinetti, G.M., (2003). A therapeutic role for cyclooxygenase-2 inhibitors in a transgenic mouse model of amyotrophic lateral sclerosis. FASEB J. Vol. 17, No. 6, pp. 725-7.

Pramatarova, A., Laganiere, J., Roussel, J., Brisebois, K. \& Rouleau, G.A., (2001). Neuronspecific expression of mutant superoxide dismutase 1 in transgenic mice does not lead to motor impairment. J Neurosci. Vol. 21, No. 10, pp. 3369-74.

Ralph, G.S., Radcliffe, P.A., Day, D.M., Carthy, J.M., Leroux, M.A., Lee, D.C., Wong, L.F., Bilsland, L.G., Greensmith, L., Kingsman, S.M., Mitrophanous, K.A., Mazarakis, N.D. \& Azzouz, M., (2005). Silencing mutant SOD1 using RNAi protects against neurodegeneration and extends survival in an ALS model. Nat Med. Vol. 11, No. 4, pp. 429-33.

Raoul, C., Abbas-Terki, T., Bensadoun, J.C., Guillot, S., Haase, G., Szulc, J., Henderson, C.E. \& Aebischer, P., (2005). Lentiviral-mediated silencing of SOD1 through RNA interference retards disease onset and progression in a mouse model of ALS. Nat Med. Vol. 11, No. 4, pp. 423-8.

Rothstein, J.D., Tsai, G., Kuncl, R.W., Clawson, L., Cornblath, D.R., Drachman, D.B., Pestronk, A., Stauch, B.L. \& Coyle, J.T., (1990). Abnormal excitatory amino acid metabolism in amyotrophic lateral sclerosis. Ann Neurol. Vol. 28, No. 1, pp. 18-25.

Rothstein, J.D., Van Kammen, M., Levey, A.I., Martin, L.J. \& Kuncl, R.W., (1995). Selective loss of glial glutamate transporter GLT-1 in amyotrophic lateral sclerosis. Ann Neurol. Vol. 38, No. 1, pp. 73-84.

Rothstein, J.D., Patel, S., Regan, M.R., Haenggeli, C., Huang, Y.H., Bergles, D.E., Jin, L., Dykes Hoberg, M., Vidensky, S., Chung, D.S., Toan, S.V., Bruijn, L.I., Su, Z.Z., Gupta, P. \& Fisher, P.B., (2005). Beta-lactam antibiotics offer neuroprotection by increasing glutamate transporter expression. Nature. Vol. 433, No. 7021, pp. 73-7.

Ryberg, H., Askmark, H. \& Persson, L.I., (2003). A double-blind randomized clinical trial in amyotrophic lateral sclerosis using lamotrigine: effects on CSF glutamate, aspartate, branched-chain amino acid levels and clinical parameters. Acta Neurol Scand. Vol. 108, No. 1, pp. 1-8.

Sah, D.W. \& Aronin, N., (2011). Oligonucleotide therapeutic approaches for Huntington disease. J Clin Invest. Vol. 121, No. 2, pp. 500-7.

Sasaki, S., Shibata, N., Komori, T. \& Iwata, M., (2000). iNOS and nitrotyrosine immunoreactivity in amyotrophic lateral sclerosis. Neurosci Lett. Vol. 291, No. 1, pp. 44-8. 
Shaw, P.J., Forrest, V., Ince, P.G., Richardson, J.P. \& Wastell, H.J., (1995). CSF and plasma amino acid levels in motor neuron disease: elevation of CSF glutamate in a subset of patients. Neurodegeneration. Vol. 4, No. 2, pp. 209-16.

Smith, R.A., Miller, T.M., Yamanaka, K., Monia, B.P., Condon, T.P., Hung, G., Lobsiger, C.S., Ward, C.M., McAlonis-Downes, M., Wei, H., Wancewicz, E.V., Bennett, C.F. \& Cleveland, D.W., (2006). Antisense oligonucleotide therapy for neurodegenerative disease. J Clin Invest. Vol. 116, No. 8, pp. 2290-6.

Sreedharan, J., Blair, I.P., Tripathi, V.B., Hu, X., Vance, C., Rogelj, B., Ackerley, S., Durnall, J.C., Williams, K.L., Buratti, E., Baralle, F., de Belleroche, J., Mitchell, J.D., Leigh, P.N., Al-Chalabi, A., Miller, C.C., Nicholson, G. \& Shaw, C.E., (2008). TDP-43 mutations in familial and sporadic amyotrophic lateral sclerosis. Science. Vol. 319, No. 5870, pp. $1668-72$.

Suzuki, M., McHugh, J., Tork, C., Shelley, B., Klein, S.M., Aebischer, P. \& Svendsen, C.N., (2007). GDNF secreting human neural progenitor cells protect dying motor neurons, but not their projection to muscle, in a rat model of familial ALS. PLoS One. Vol. 2, No. 8, pp. e689.

Takahashi, K. \& Yamanaka, S., (2006). Induction of pluripotent stem cells from mouse embryonic and adult fibroblast cultures by defined factors. Cell. Vol. 126, No. 4, pp. 663-76.

Takahashi, K., Tanabe, K., Ohnuki, M., Narita, M., Ichisaka, T., Tomoda, K. \& Yamanaka, S., (2007). Induction of pluripotent stem cells from adult human fibroblasts by defined factors. Cell. Vol. 131, No. 5, pp. 861-72.

Towne, C., Setola, V., Schneider, B.L. \& Aebischer, P., (2011). Neuroprotection by gene therapy targeting mutant SOD1 in individual pools of motor neurons does not translate into therapeutic benefit in fALS mice. Mol Ther. Vol. 19, No. 2, pp. 274-83.

Turner, B.J., Ackerley, S., Davies, K.E. \& Talbot, K., (2010). Dismutase-competent SOD1 mutant accumulation in myelinating Schwann cells is not detrimental to normal or transgenic ALS model mice. Hum Mol Genet. Vol. 19, No. 5, pp. 815-24.

Urushitani, M., Sik, A., Sakurai, T., Nukina, N., Takahashi, R. \& Julien, J.P., (2006). Chromogranin-mediated secretion of mutant superoxide dismutase proteins linked to amyotrophic lateral sclerosis. Nat Neurosci. Vol. 9, No. 1, pp. 108-18.

Van Den Bosch, L., Tilkin, P., Lemmens, G. \& Robberecht, W., (2002). Minocycline delays disease onset and mortality in a transgenic model of ALS. Neuroreport. Vol. 13, No. 8, pp. 1067-70.

Vance, C., Rogelj, B., Hortobagyi, T., De Vos, K.J., Nishimura, A.L., Sreedharan, J., Hu, X., Smith, B., Ruddy, D., Wright, P., Ganesalingam, J., Williams, K.L., Tripathi, V., AlSaraj, S., Al-Chalabi, A., Leigh, P.N., Blair, I.P., Nicholson, G., de Belleroche, J., Gallo, J.M., Miller, C.C. \& Shaw, C.E., (2009). Mutations in FUS, an RNA processing protein, cause familial amyotrophic lateral sclerosis type 6. Science. Vol. 323, No. 5918, pp. 1208-11.

Wang, H., Ghosh, A., Baigude, H., Yang, C.S., Qiu, L., Xia, X., Zhou, H., Rana, T.M. \& Xu, Z., (2008). Therapeutic gene silencing delivered by a chemically modified small interfering RNA against mutant SOD1 slows amyotrophic lateral sclerosis progression. J Biol Chem. Vol. 283, No. 23, pp. 15845-52.

Wang, L., Sharma, K., Grisotti, G. \& Roos, R.P., (2009). The effect of mutant SOD1 dismutase activity on non-cell autonomous degeneration in familial amyotrophic lateral sclerosis. Neurobiol Dis. Vol. 35, No. 2, pp. 234-40. 
Wang, L., Gutmann, D.H. \& Roos, R.P., (2011). Astrocyte loss of mutant SOD1 delays ALS disease onset and progression in G85R transgenic mice. Hum Mol Genet. Vol. 20, No. 2, pp. 286-93.

Wernig, M., Meissner, A., Foreman, R., Brambrink, T., Ku, M., Hochedlinger, K., Bernstein, B.E. \& Jaenisch, R., (2007). In vitro reprogramming of fibroblasts into a pluripotent ES-cell-like state. Nature. Vol. 448, No. 7151, pp. 318-24.

Weydt, P., Yuen, E.C., Ransom, B.R. \& Moller, T., (2004). Increased cytotoxic potential of microglia from ALS-transgenic mice. Glia. Vol. 48, No. 2, pp. 179-82.

Xiao, Q., Zhao, W., Beers, D.R., Yen, A.A., Xie, W., Henkel, J.S. \& Appel, S.H., (2007). Mutant SOD1(G93A) microglia are more neurotoxic relative to wild-type microglia. $J$ Neurochem. Vol. 102, No. 6, pp. 2008-19.

Xu, L., Ryugo, D.K., Pongstaporn, T., Johe, K. \& Koliatsos, V.E., (2009). Human neural stem cell grafts in the spinal cord of SOD1 transgenic rats: differentiation and structural integration into the segmental motor circuitry. J Comp Neurol. Vol. 514, No. 4, pp. 297-309.

Xu, L., Shen, P., Hazel, T., Johe, K. \& Koliatsos, V.E., (2011). Dual transplantation of human neural stem cells into cervical and lumbar cord ameliorates motor neuron disease in SOD1 transgenic rats. Neurosci Lett. Vol. 494, No. 3, pp. 222-6.

Yamanaka, K., Boillee, S., Roberts, E.A., Garcia, M.L., McAlonis-Downes, M., Mikse, O.R., Cleveland, D.W. \& Goldstein, L.S., (2008a). Mutant SOD1 in cell types other than motor neurons and oligodendrocytes accelerates onset of disease in ALS mice. Proc Natl Acad Sci U S A. Vol. 105, No. 21, pp. 7594-9.

Yamanaka, K., Chun, S.J., Boillee, S., Fujimori-Tonou, N., Yamashita, H., Gutmann, D.H., Takahashi, R., Misawa, H. \& Cleveland, D.W., (2008b). Astrocytes as determinants of disease progression in inherited amyotrophic lateral sclerosis. Nat Neurosci. Vol., No., pp.

Yamanaka, S. \& Blau, H.M., (2010). Nuclear reprogramming to a pluripotent state by three approaches. Nature. Vol. 465, No. 7299, pp. 704-12.

Yu, J., Vodyanik, M.A., Smuga-Otto, K., Antosiewicz-Bourget, J., Frane, J.L., Tian, S., Nie, J., Jonsdottir, G.A., Ruotti, V., Stewart, R., Slukvin, II \& Thomson, J.A., (2007). Induced pluripotent stem cell lines derived from human somatic cells. Science. Vol. 318, No. 5858, pp. 1917-20.

Zhao, T., Zhang, Z.N., Rong, Z. \& Xu, Y., (2011). Immunogenicity of induced pluripotent stem cells. Nature. Vol. 474, No. 7350, pp. 212-5.

Zhao, W., Xie, W., Xiao, Q., Beers, D.R. \& Appel, S.H., (2006). Protective effects of an antiinflammatory cytokine, interleukin-4, on motoneuron toxicity induced by activated microglia. J Neurochem. Vol. 99, No. 4, pp. 1176-87.

Zhao, W., Beers, D.R., Henkel, J.S., Zhang, W., Urushitani, M., Julien, J.P. \& Appel, S.H., (2010). Extracellular mutant SOD1 induces microglial-mediated motoneuron injury. Glia. Vol. 58, No. 2, pp. 231-43.

Zhu, S., Stavrovskaya, I.G., Drozda, M., Kim, B.Y., Ona, V., Li, M., Sarang, S., Liu, A.S., Hartley, D.M., Wu, D.C., Gullans, S., Ferrante, R.J., Przedborski, S., Kristal, B.S. \& Friedlander, R.M., (2002). Minocycline inhibits cytochrome c release and delays progression of amyotrophic lateral sclerosis in mice. Nature. Vol. 417, No. 6884, pp. 74-8.

Zinman, L. \& Cudkowicz, M., (2011). Emerging targets and treatments in amyotrophic lateral sclerosis. Lancet Neurol. Vol. 10, No. 5, pp. 481-90. 
AMYOTROPHIC

LATERAL SCLEROSIS

Eaced by Marton H. maver

\section{Amyotrophic Lateral Sclerosis}

Edited by Prof. Martin Maurer
ISBN 978-953-307-806-9

Hard cover, 718 pages

Publisher InTech

Published online 20, January, 2012

Published in print edition January, 2012

Though considerable amount of research, both pre-clinical and clinical, has been conducted during recent years, Amyotrophic Lateral Sclerosis (ALS) remains one of the mysterious diseases of the 21st century. Great efforts have been made to develop pathophysiological models and to clarify the underlying pathology, and with novel instruments in genetics and transgenic techniques, the aim for finding a durable cure comes into scope. On the other hand, most pharmacological trials failed to show a benefit for ALS patients. In this book, the reader will find a compilation of state-of-the-art reviews about the etiology, epidemiology, and pathophysiology of ALS, the molecular basis of disease progression and clinical manifestations, the genetics familial ALS, as well as novel diagnostic criteria in the field of electrophysiology. An overview over all relevant pharmacological trials in ALS patients is also included, while the book concludes with a discussion on current advances and future trends in ALS research.

\section{How to reference}

In order to correctly reference this scholarly work, feel free to copy and paste the following:

Amanda M. Haidet-Phillips and Nicholas J. Maragakis (2012). Glial Cells as Therapeutic Targets for ALS, Amyotrophic Lateral Sclerosis, Prof. Martin Maurer (Ed.), ISBN: 978-953-307-806-9, InTech, Available from: http://www.intechopen.com/books/amyotrophic-lateral-sclerosis/glial-cells-as-therapeutic-targets-for-als

\section{INTECH}

open science | open minds

\author{
InTech Europe \\ University Campus STeP Ri \\ Slavka Krautzeka 83/A \\ 51000 Rijeka, Croatia \\ Phone: +385 (51) 770447 \\ Fax: +385 (51) 686166 \\ www.intechopen.com
}

\author{
InTech China \\ Unit 405, Office Block, Hotel Equatorial Shanghai \\ No.65, Yan An Road (West), Shanghai, 200040, China \\ 中国上海市延安西路65号上海国际贵都大饭店办公楼405单元 \\ Phone: +86-21-62489820 \\ Fax: +86-21-62489821
}


(C) 2012 The Author(s). Licensee IntechOpen. This is an open access article distributed under the terms of the Creative Commons Attribution 3.0 License, which permits unrestricted use, distribution, and reproduction in any medium, provided the original work is properly cited. 